\title{
Análise dos riscos físicos da operação de checkout: uma proposta conceitual de posto de trabalho
}

\section{Analysis of the physical risks of the checkout operation: a conceptual proposal of the workplace}

\author{
Lincoln da Silva ${ }^{1}$ \\ Franciele Forcelini ${ }^{2}$ \\ Thiago Varnier ${ }^{3}$ \\ Leila Amaral Gontijo ${ }^{4}$ \\ Giselle Schmidt Alves Díaz Merino ${ }^{5}$ \\ Eugenio Andrés Díaz Merino
}




\section{Resumo}

O setor supermercadista apresenta mais de duzentos mil postos de trabatho no Brasil e, as condições físicas dos operadores de checkout denotam um relevante objeto de estudo ergonômico. Neste sentido, este estudo realizado em um supermercado localizado na cidade de Florianópolis/SC, teve como objetivo identificar os riscos físicos da operação de checkout para o desenvolvimento de um projeto conceitual de um novo posto de trabalho. Para tanto, foi utilizada a Análise Ergonômica do Trabalho (AET) para analisar a demanda, a tarefa e as atividades da operação de checkout, complementada por uma análise cinemática. Os resultados demonstram posições estáticas com protrusão da cabeça e flexão anterior do tronco, somados ao aumento progressivo da abdução dos ombros, em função da passagem das compras, e movimentos repetitivos de rotação cervical para direita. Dentre os atributos do novo projeto proposto destacam-se o posicionamento do monitor à frente do operador (para reduzir rotações cervicais), a balança posicionada sob a esteira (para diminuir levantamento de cargas e esforço repetitivo) e o aumento da área de trabalho (para permitir maior variação de posturas). Contudo, a partir da AET, foi possível a identificação dos riscos físicos da operação de checkout, o que determinou requisitos para o desenvolvimento de um projeto conceitual de um novo posto de trabalho.

Palavras-chave: Ergonomia; Análise ergonômica de trabalho; Posto de trabalho; Checkout; Queixas musculoesqueléticas.

\section{Abstract}

The supermarket sector has more than two hundred thousand jobs in Brazil, thus the physical conditions of the checkout operators denote a relevant object of ergonomic study. So, this study carried out in a supermarket located in the city of Florianopolis/SC, aimed to identify the physical risks of the checkout operation for the development of a conceptual project of a new workstation. For that, the Ergonomic Work Analysis (EWA) was used to analyze the demand, the task and the activities of the checkout operation, complemented by a kinematic analysis. The results demonstrate, through the kinematic analysis, the static positions with protrusion of the head and anterior flexion of the trunk, added to the progressive increase of abduction of the shoulders due to the passage of the purchases and the repetitive movements of cervical rotation to the right. Amongst the attributes of the new design we have the positioning of the monitor in front of the operator (to reduce cervical rotations), the scale positioned under the belt (to decrease lifting loads and repetitive effort), as well as the increase of the work area (to allow for a variation of postures). However, from the EWA, it was possible to identify the physical risks of the checkout operation, which determined requirements for the development of a conceptual project of a new workstation.

Key-words: Ergonomics; Ergonomic work analysis; Workstation; Checkout; Musculoskeletal injuries.
1Doutorando em Engenharia, UFSC (lincoln_floripa@yahoo.com.br) 2Doutoranda em Design, UFSC (francieleforcelini@gmail.com) ${ }^{3}$ Doutorando em Design, UFSC
${ }^{4}$ Doutora em Ergonomia, UFSC (leila.gontijo@ufsc.br) ${ }^{5}$ Doutora em Engenharia, UDESC (gisellemerino@gmail.com) ${ }^{6}$ Doutor em Engenharia, UFSC (eugenio.merino@ufsc.br) 


\section{INTRODUÇÃO}

Constituída por dois radicais ergon (trabalho) e nomos (lei/regra), o termo ergonomia designa a ciência do trabalho, que tem como objetivo a definição de suas regras (GUÉRIN et al., 2001). É uma área ampla e complexa que contempla uma série de ferramentas e análises para o estudo e avaliação do trabalho. Entre os processos de intervenção ergonômica, destaca-se aqui a Análise Ergonômica do Trabalho (AET), que tem como objetivo a análise, diagnóstico e correção de situações reais de trabalho. Além disso, visa identificar riscos à saúde do trabalhador (IIDA; GUIMARÃES, 2016).

As condições de trabalho incluem aspectos relacionados às atividades desenvolvidas, ao mobiliário, aos equipamentos, às condições ambientais e à própria organização do trabalho (GUÉRIN et al., 2001). Neste contexto, o ergonomista deve analisar e diagnosticar bem como sugerir mudanças que visem a melhoria da qualidade de vida e da saúde física e mental do trabalhador. Assim, torna-se necessária a análise dos postos de trabalho a fim de identificar fatores de risco com intuito de evitar ou sanar problemas que comprometem a saúde do trabalhador (CORRÊA; BOLETTI, 2015).

A AET é uma intervenção ergonômica que pode ser aplicada à diversos segmentos, apresentando contribuições aos trabalhadores e às organizações. Dentre esses segmentos, destaca-se o varejo supermercadista, que emprega os operadores de caixa de supermercado (checkouts ${ }^{1}$ ), enquadrados na Classificação Brasileira de Ocupações (CBO) como operador de caixa (4211-25), pertencente à categoria de caixas e bilheteiros (MTE/SPPE, 2017). Este setor designa um serviço indispensável que apresenta um número crescente de postos de trabalho, o qual passou de 212.964 no ano de 2014 para 215.580 no ano de 2015 (ABRAS, 2017). Deste modo, as condições de trabalho dos operadores de checkout denotam um relevante objeto de estudo ergonômico, em todos os domínios - físico, cognitivo e organizacional.

A relevância deste setor também é confirmada por meio da existência de um anexo específico à função dos operadores de checkout na norma regulamentadora 17 (NR 17), a qual estabelece parâmetros e diretrizes mínimas para adequação das condições de trabalho, visando à prevenção dos problemas de saúde e segurança (BRASIL, 2007). Diante disso, apresenta orientações em relação à variáveis ambientais, capacitações, bem como requisitos para a adequação e desenvolvimento de postos de trabalho.

Em relação aos aspectos físicos, Carlos et al. (2012) abordam como problemas relacionados a operação de checkout, os sucessivos deslocamentos, posturas prejudiciais e movimentos repetitivos das mãos. De acordo com Moreira, Bastos e Nepomuceno (2011), às lesões musculoesqueléticas relacionadas ao trabalho dos operadores de checkout podem ser resultado do excesso de estresse em função da repetitividade, reclamação dos clientes e da qualidade dos postos de trabalho.

Souza e Mazini Filho (2015) demonstraram que as partes mais acometidas com distúrbios musculoesqueléticos em operadores de checkout são: a região superior e inferior das costas, pescoço, ombros e pernas. Garcia, Parada e Gutiérrez (2003)

$1 \quad$ Neste artigo, o termo checkout será utilizado para se referir ao posto de trabalho do caixa de supermercado. 
ressaltam a repetitividade nas tarefas e o possível desenvolvimento de problemas nas articulações de punhos, mãos, braços, ombros e vértebras cervicais. Os estudos de Teixeira et al. (2009) demonstram que as condições de trabalho desajustadas com a NR 17, relacionam-se com sintomas musculoesqueléticos, principalmente na região superior das costas. Logo, os autores apontam a necessidade de alterações nos postos de trabalho a fim de adequá-los à NR-17 (BRASIL, 2007), minimizando os riscos musculoesqueléticos identificados.

Portanto, nota-se a relevância da adequação dos postos de trabalho a fim de reduzir as lesões musculoesqueléticas, o absenteísmo e a baixa produtividade que afeta tanto os operadores como os empregadores. Para isso, a ergonomia colabora com recomendações para postos, reduzindo os esforços biomecânicos e cognitivos relacionados à execução da tarefa (IIDA; GUIMARÃES, 2016). Semensato (2011) destaca que pesquisas, analises e orientações ergonômicas, assim como postos e condições de trabalhos adequados à norma NR-17 (BRASIL, 2007), podem minimizar doenças ocupacionais. Contudo, entende-se que a AET consiste em um instrumento benéfico tanto à organização quanto ao trabalhador, visto que pretende diagnosticar problemas e apresentar recomendações para melhorar as condições de trabalho e a qualidade de vida dos operadores de checkout.

Diante do exposto, esta pesquisa tem como objetivo identificar os riscos físicos da operação de checkout de supermercado para o desenvolvimento de um projeto conceitual de um posto de trabalho. Para tanto, com base em dados de uma AET, foram caracterizadas a demanda, a tarefa e as atividades dos operadores de checkout, delimitando-se a análise dos aspectos físicos, a afim de propor requisitos para um novo posto de trabalho.

\section{PROCEDIMENTOS METODOLÓGICOS}

Com o propósito de responder ao objetivo deste artigo, realizou-se um estudo de natureza aplicada, com abordagem qualitativa e quantitativa, exploratória e descritiva (MARCONI; LAKATOS, 2011). Para tanto, utilizou-se um estudo de caso, tendo como sujeito um operador de checkout de um supermercado de médio porte, localizado na cidade de Florianópolis, Santa Catarina. A estratégia de estudo de caso foi definida pela necessidade de entendimento em profundidade de um determinado fenômeno em seu contexto real, considerando que os limites entre o fenômeno e o contexto não são claramente evidentes (YIN, 2010).

Para a realização do estudo no supermercado, foi apresentada à empresa uma carta de autorização com os objetivos da pesquisa. Logo, foram entregues os Termos de Consentimento Livre e Esclarecido (TCLE) e Termos de Consentimento para Uso de Imagem e Voz para os envolvidos, com a apresentação dos objetivos e a relevância da participação do operador na pesquisa, conforme instruções da Resolução do Conselho Nacional da Saúde (CNS) n 466, de 12 de dezembro de 2012, que dispõe Diretrizes e Normas Regulamentadoras Envolvendo Seres Humanos (BRASIL, 2013). 


\subsection{Etapas da pesquisa}

A pesquisa segmenta-se em três etapas. A primeira etapa (Levantar) contempla a realização da pesquisa bibliográfica, elaborada a partir de materiais já publicados, sobre os riscos físicos associados ao trabalho dos operadores de checkout de supermercados. Na segunda etapa (Caracterizar e diagnosticar), por meio de uma AET, foram caracterizadas a demanda, a tarefa e as atividades do operador de checkout, identificando os riscos musculoesqueléticos associados ao posto de trabalho de checkout. Por fim, na etapa 3 (Propor), com base nas recomendações ergonômicas da AET, foi proposto um projeto conceitual de um posto de checkout.

\subsection{Materiais e métodos}

Na etapa 1 (Levantar), foi realizado o levantamento bibliográfico nos meses de agosto e setembro de 2017. Este levantamento ocorreu de forma assistemática com base em teses e dissertações, artigos de periódicos nacionais e internacionais, utilizando-se os descritores: ergonomia; análise ergonômica do trabalho; posto de trabalho; checkout; e queixas musculoesqueléticas nas buscas.

$\mathrm{Na}$ etapa 2 (Caracterizar e diagnosticar), foram caracterizadas a demanda, a tarefa e as atividades do operador de checkout, identificando os riscos musculoesqueléticos associados ao posto de trabalho por meio da AET, seguindo o modelo proposto por Santos e Fialho (1997), que contempla as etapas de análise da demanda (1), análise da tarefa (2), análise das atividades (3), elaboração de um diagnóstico (4) e recomendações ergonômicas (5), apresentadas na figura 1.

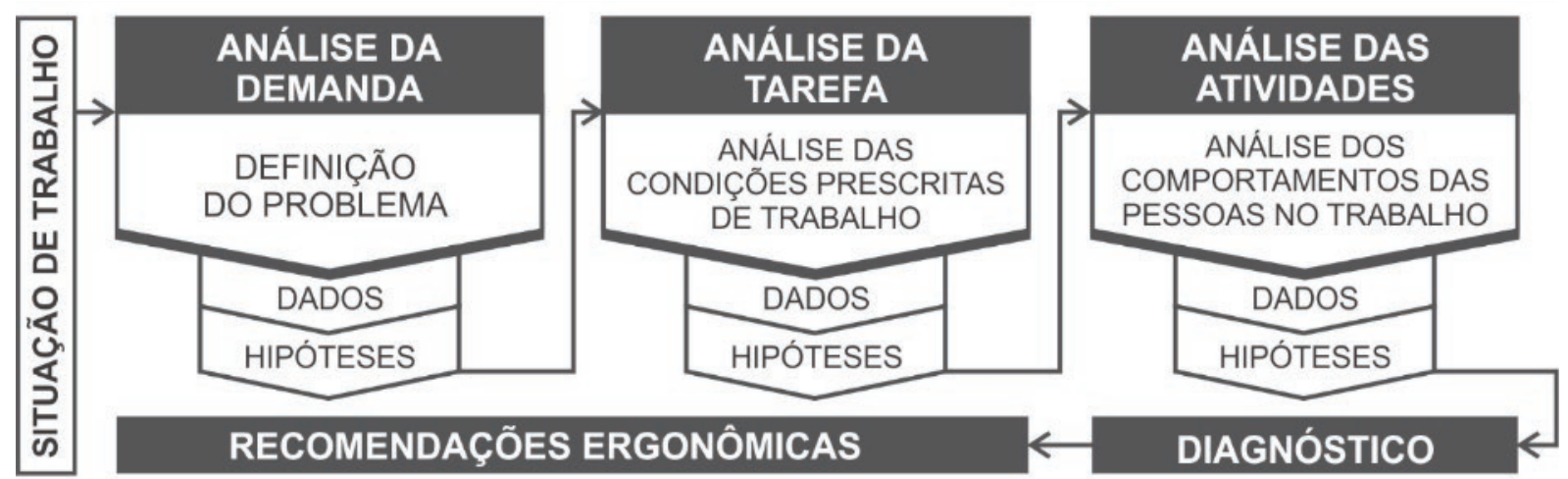

Figura 1: Análise Ergonômica do Trabalho

Fonte: adaptado de Santos e Fialho (1997).

- Análise da demanda: A demanda é o ponto de partida de toda a AET, que permite o entendimento do(s) problema(s) para a elaboração do plano de ações ergonômicas. É uma fase exploratória que compreende o mapeamento dos problemas ergonômicos do trabalho. Para a definição da demanda, foram utilizadas as técnicas de observação direta e captura de imagens (fotografias e vídeos) da operadora em atividade, bem como entrevistas semiestruturadas com a operadora e o seu superior direto. Além disso, foi realizada a aplicação do questionário Nórdico. A operadora foi orientada a responder ao questionário nórdico de sintomas musculoesqueléticos, adaptado para o 
português por Barros e Alexandre (2003), com o propósito da identificação da presença de dores.

- Análise da tarefa: Tarefa é aquilo que se apresenta ao trabalhador, o que lhe é oferecido. A tarefa prescrita foi levantada a partir de uma análise documental, considerando Programa de Prevenção de Riscos Ambientais (PPRA) da empresa. Além disso, foram levantadas as condições ambientais do local de trabalho. Para o levantamento da temperatura, umidade relativa do ar, ventilação e níveis de iluminação foi utilizado o Termo Higro Anemômetro e Luxímetro, THAL 300 da marca Instrutherm. Para a captura dos níveis de ruído, foi utilizado o medidor de nível sonoro (decibelímetro) digital portátil DEC460, da Instrutherm. Por fim, para a caracterização do piso, teto e paredes, utilizou-se dos recursos de observação direta e levantamento fotográfico.

- Análise da atividade: A análise da atividade expressa como o operador faz para atingir os objetivos da tarefa que lhe foi confiada, em condições que podem ser geridas e adaptadas pelo mesmo. As informações referentes a atividade foram levantadas por meio de observações no local, análise de fotografias e vídeos, bem como entrevistas semiestruturadas com a operadora analisada, medidas antropométricas realizadas com uma fita métrica da marca MVN Segmo Meter 5m/16', e teste de bioimpedância, com a balança de controle corporal da marca OMRON, modelo HBF - 514C. Diante desta interação, foi possível estabelecer um fluxo geral das atividades reais. Para verificar com maior exatidão as posturas e movimentos executados durante a jornada de trabalho (movimentos, ângulos articulares, deslocamentos e tempo de realização dos movimentos) foi utilizado o software Kinovea versão 0.8.15. Para essa análise foram colocados marcadores esféricos de isopor nos seguintes pontos articulares: acrômio (1), epicôndilo lateral (2), processo estilóide da ulna (3), processo espinhoso de da vértebra lombar 5 (L5) (4) e trocanter maior (5), conforme a figura 2. Além desses marcadores, foi colocada uma tarja de 10 centímetros com intuito de calibrar o sistema para a análise das imagens.

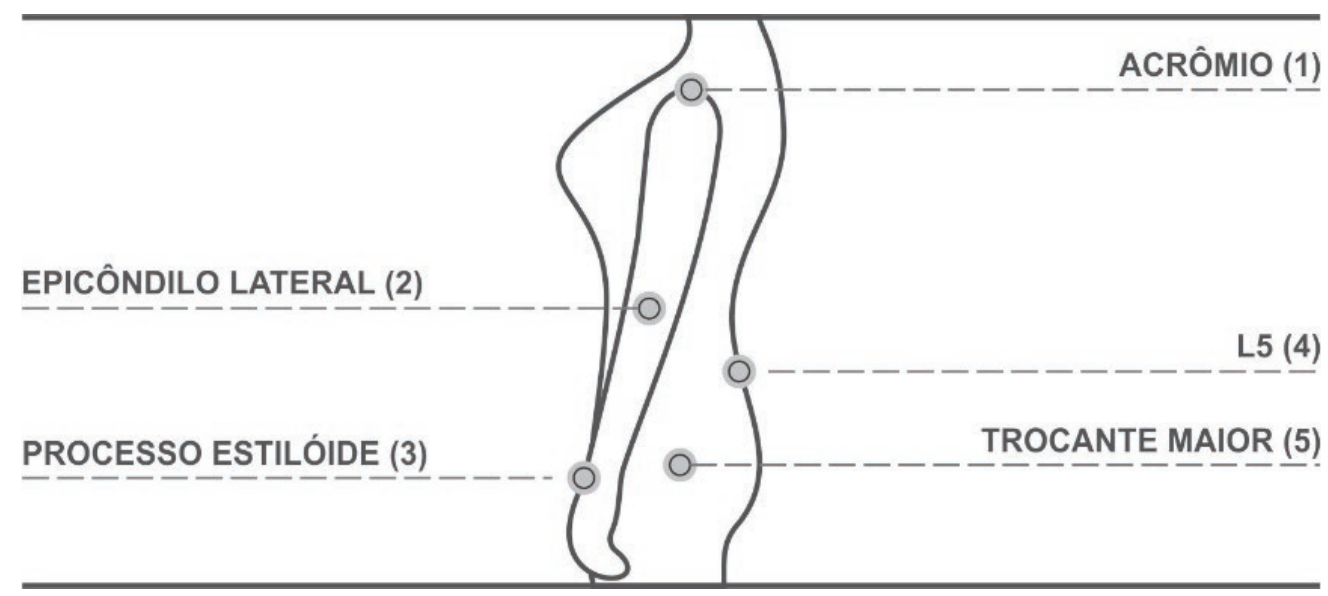

Figura 2: Posicionamento de marcadores para análise no Kinovea Fonte: os autores, 2018. 
- Diagnóstico e recomendações ergonômicas: O diagnóstico e as recomendações foram formulados a partir das análises realizadas. As recomendações consistem em ações ergonômicas de correção, conscientização, participação e concepção.

Por fim, na etapa 3 (Propor) propõe-se um projeto conceitual de um posto de checkout, desenvolvido a partir das recomendações das pesquisas bibliográficas levantadas e dados coletados a partir do desenvolvimento da AET.

\subsection{Sujeito da pesquisa}

Para a AET, selecionou-se uma operadora de checkout com 29 anos, ensino médio incompleto e atua há cinco anos nesse cargo, com carga horária de 44 horas semanais. Quanto às características físicas, possui estatura de 1.55 metros, massa corporal de 55,9 kg, massa muscular de $29,7 \%$, IMC de 23,3 e gordura corporal total de $31,2 \%$. A escolha justifica-se pela predominância de mulheres no cargo. No período do estudo, o corpo funcional da empresa era composto por 79 trabalhadores, sendo 21 operadores de checkout e, destes, 16 do sexo feminino.

\section{RESULTADOS}

\subsection{Análise da demanda}

A demanda permite o entendimento do(s) problema(s) para a elaboração do plano de ações ergonômicas. De acordo com Moraes e Mont'Alvão (2000), esta etapa compreende o mapeamento dos problemas ergonômicos do trabalho. Neste tipo de análise, segundo Wisner (1987), deve-se analisar a representatividade do autor da demanda, a origem da demanda (real e formal), os problemas (aparentes e fundamentais), as perspectivas de ação e os meios disponíveis. Ainda, o autor destaca que a demanda pode ser formulada a partir do ponto de vista da direção e do trabalhador.

Deste modo, foi definida a demanda deste estudo, que se encontra relacionada aos desconfortos físicos relacionados às atividades de trabalho. Em relação à direção, foram apontados problemas referentes aos movimentos repetitivos próprios da atividade. No que tange à operadora, os relatos verbais apontaram dores musculoesqueléticas na região cervical (pescoço) e punhos, que foram confirmadas por meio do questionário nórdico, cujas respostas demonstraram desconfortos nessas áreas nos últimos 12 meses.

\subsection{Análise da tarefa}

Define-se tarefa como aquilo que se apresenta ao trabalhador, o que the é oferecido: a máquina e seu funcionamento, o meio físico ao redor do posto de trabalho, as instruções oferecidas (organização do trabalho) e, evidentemente, aquilo que designa a própria tarefa, ou seja, os objetivos definidos, controles e sanções (MONTMOLLIN, 1990). Segundo Abrahão et al. (2009), é o conjunto de prescrições (o traba- 
lhador deve fazer), conforme normas e padrões de quantidade e qualidade, por meio de equipamentos e ferramentas específicas, ou seja, é o trabalho prescrito.

A empresa dispõe de um Programa de Prevenção de Riscos Ambientais (PPRA), o qual prescreve ao cargo as seguintes tarefas: receber valores de vendas de produtos e serviços; controlar numerários e valores; atender o público; pesar produtos; receber pagamento dos produtos adquiridos na loja, prestar informações ao público, preencher relatórios administrativos, cheques e outras formas de pagamento, ajudar o embalador quando necessário.

Em relação às variáveis ambientais, foram verificadas as propriedades do teto (isopor branco), piso (cinza escuro acetinado) e paredes (envidraçada e em alvenaria branca), a temperatura ambiente $(24,5 \circ \mathrm{C})$, umidade relativa do ar (65\%), velocidade do ar (nula), nível de ruído (94.2 dB), iluminação na área do teclado (305 lux) e iluminação na superfície do balcão (225 lux).

O posto de trabalho contempla: balcão (1), monitor (2), impressora (3), gaveta caixa (4), teclado (5), leitor de código de barras (6), leitor de código de barras móvel (7), máquina de cartão (8), CPU (9), apoio para os pés (10) e cadeira caixa (11), apresentados na figura 3 .

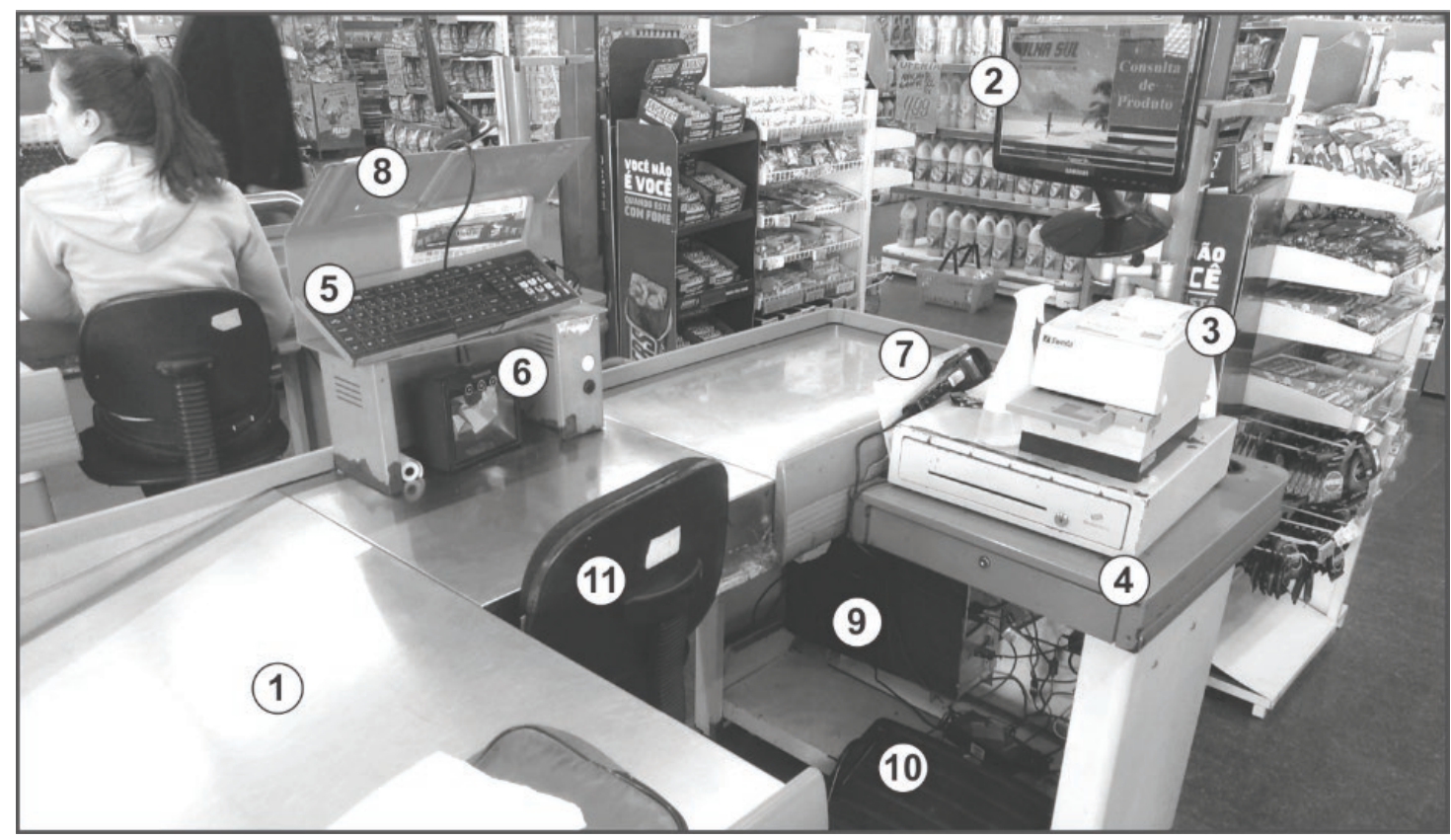

Figura 3: Disposição dos elementos no posto de trabalho Fonte: os autores, 2018.

\subsection{Análise da atividade}

A análise da atividade, segundo Guérin et al. (2001) expressa como o operador, tendo características particulares, faz para atingir os objetivos da tarefa que lhe foi confiada, em condições que podem ser geridas e adaptadas pelo mesmo. Montmollin (1990) corrobora que esta análise compreende as atividades exercidas para desempenhar e modificar a tarefa real.

Por meio do levantamento de dados se estabeleceu um fluxo das atividades reais do operador de caixa, sintetizado na figura 4. 


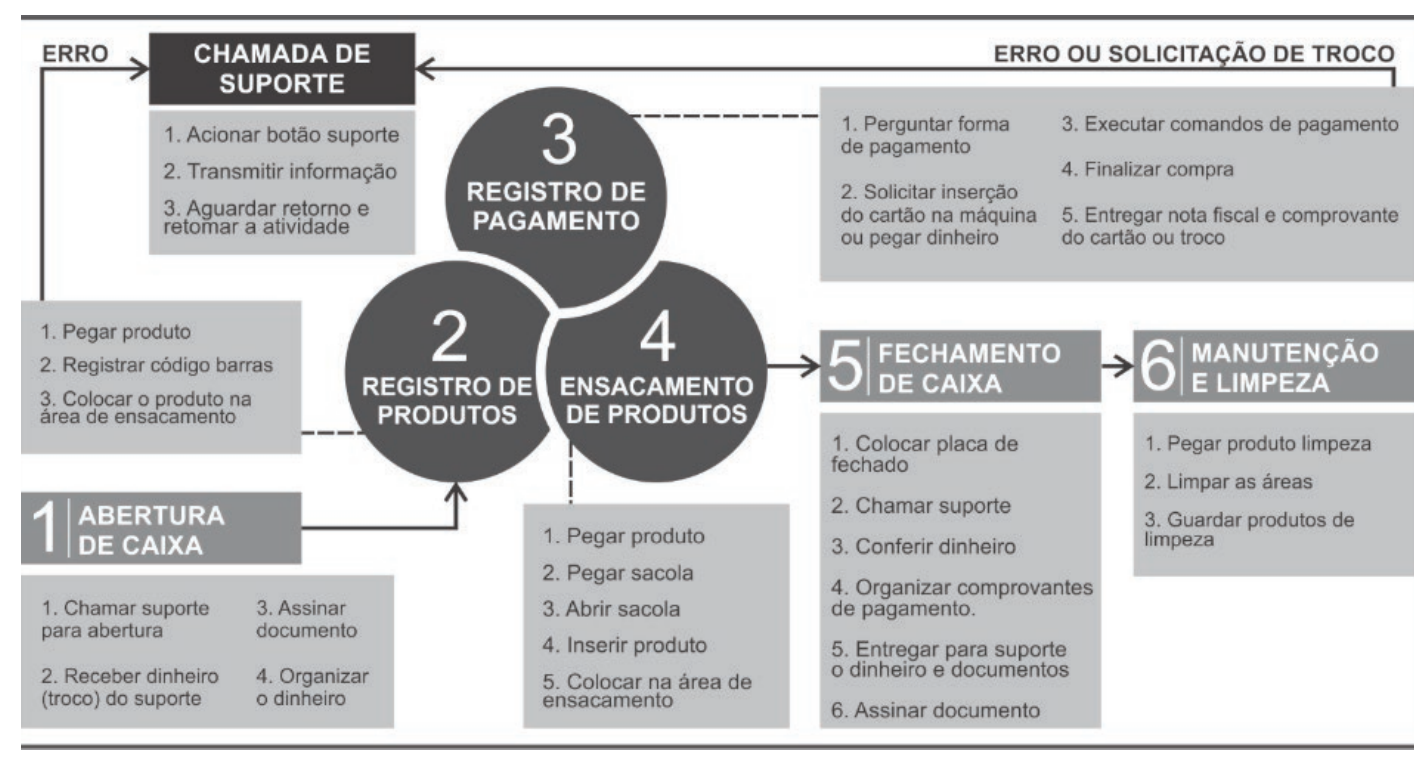

Figura 4: Fluxo das atividades do operador de checkout. Fonte: os autores, 2018.

\subsubsection{Análise Cinemática}

A análise cinemática foi realizada por meio do software Kinovea versão 0.8.15 (KINOVEA, 2018), observando-se as filmagens da vista sagital esquerda (figura 5) e cranial (figura 6) da operadora de checkout, no momento da realização das atividades de registro de produtos (figura 4 - 2) e ensacamento de produtos (figura 4 - 4). 0 tempo de observação foi de 34,4 segundos, o que corresponde a aproximadamente $0,12 \%$ da atividade diária.

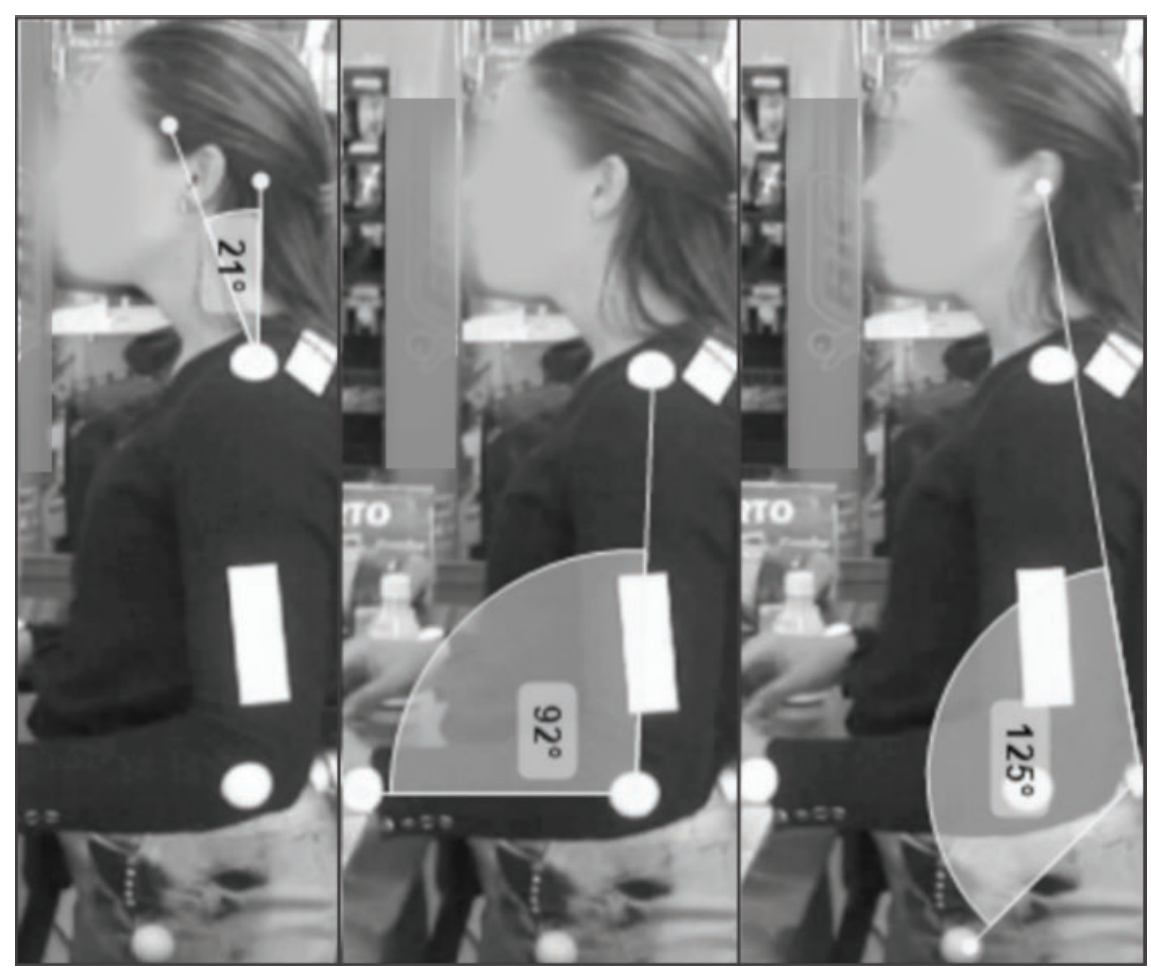

Figura 5: Ângulos medidos na vista sagital esquerda. Fonte: os autores, 2018. 


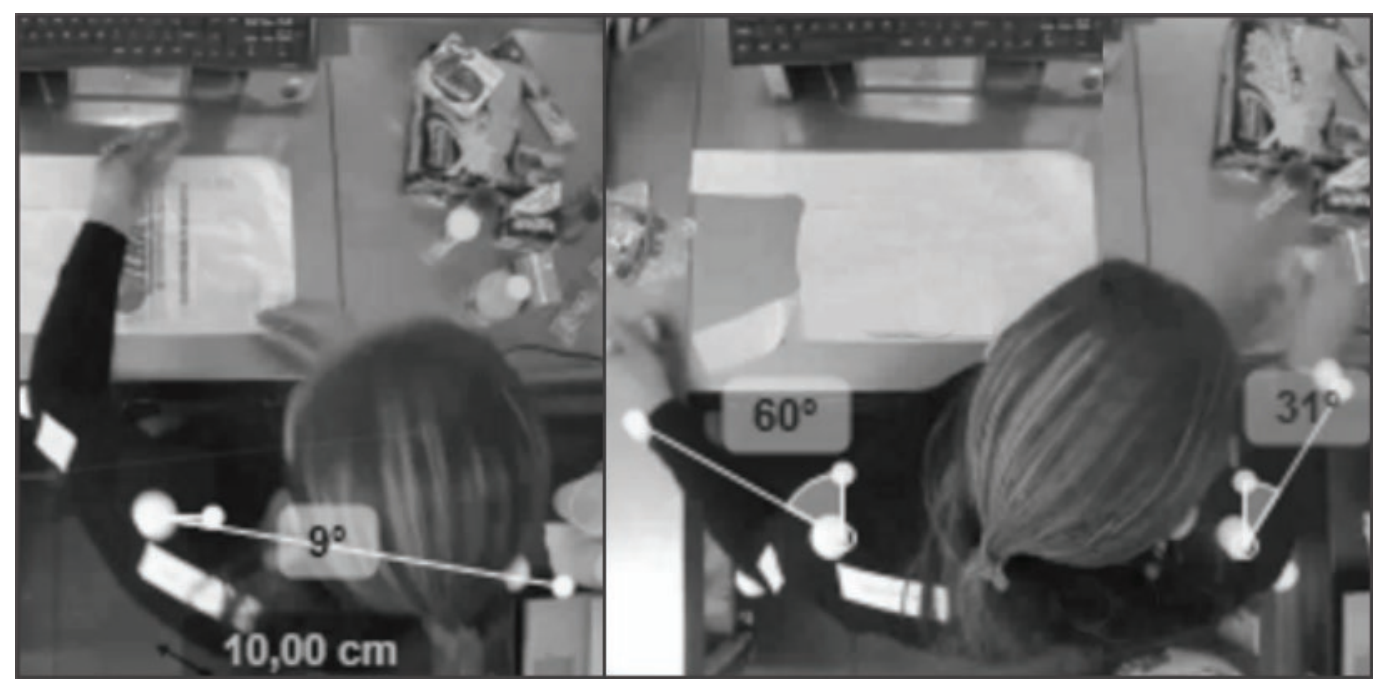

Figura 6: Ângulos medidos na vista cranial. Fonte: os autores, 2018.

O gráfico 1 apresenta os valores dos ângulos (figura 5), referentes à região cervical (acrômio; ângulo reto; meato acústico externo), cotovelo (epicôndilo lateral; acrômio; processo estiloide da ulna) e inclinação anterior do tronco (L5; meato acústico externo; trocânter) em relação ao lado esquerdo do sujeito examinado em função do tempo. Pode-se notar que houve pouca variação angular cervical e do cotovelo, mas há importante variação do ângulo de inclinação anterior do tronco.

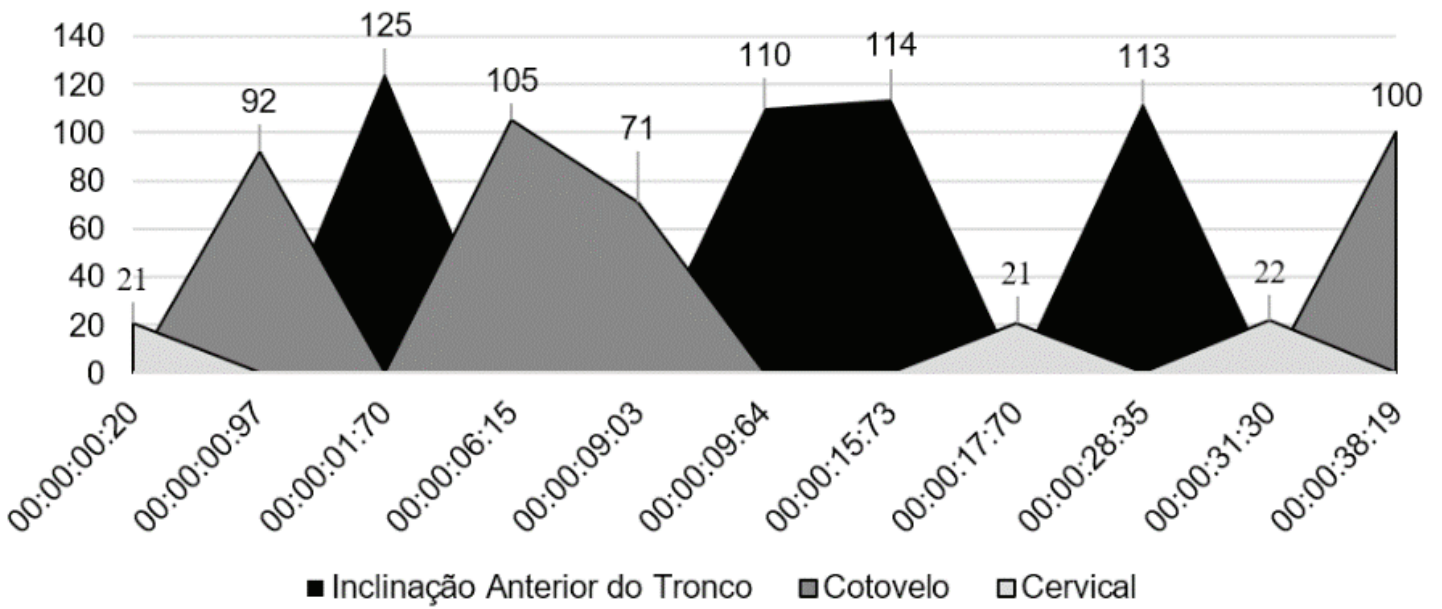

Gráfico 1: Valores dos ângulos (graus) em função do tempo (cs) - Vista sagital esquerda Fonte: Os autores, 2018.

Em relação à vista cranial, foram mensurados os ângulos de inclinação e de abdução dos ombros (figura 6). Os resultados das medidas, apresentados no gráfico 2, demonstram um aumento da angulação na rotação do tronco e abdução do ombro esquerdo a medida que os produtos são registrados e a compra finalizada. Além disso, nota-se frequentes rotações cervicais para direita, com intuito de visualizar as informações da leitura do produto no monitor (posicionado lateralmente). 


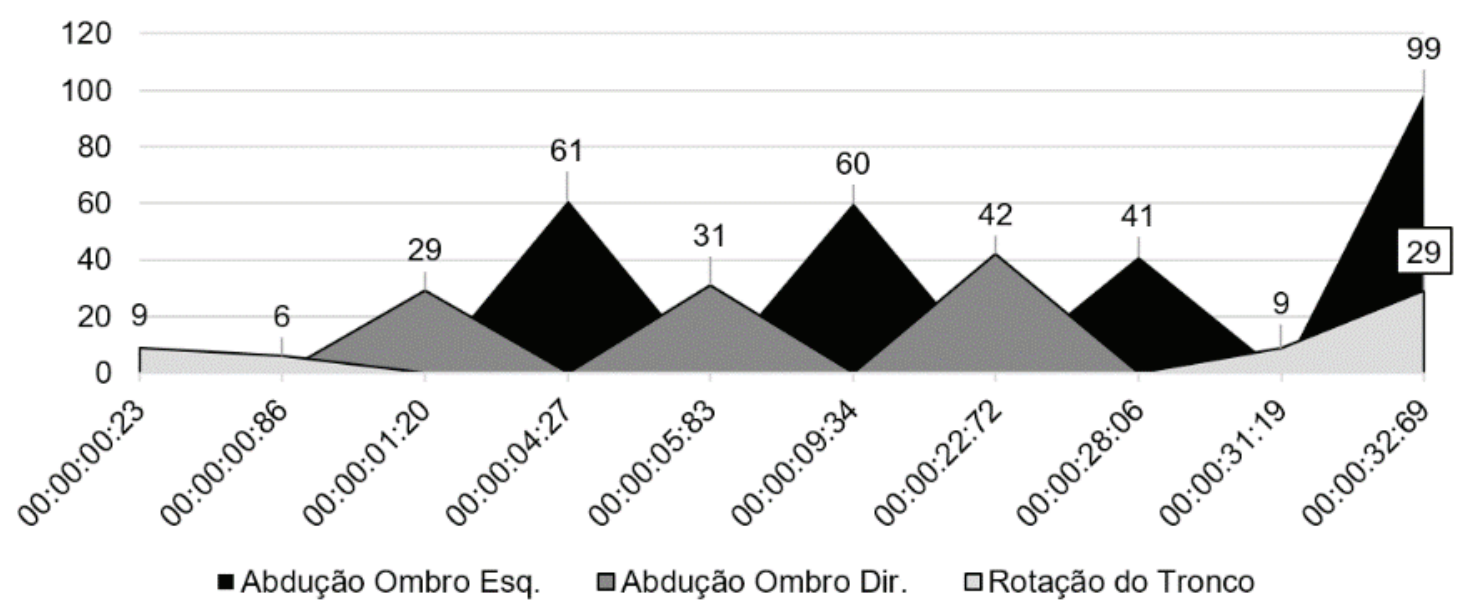

Gráfico 2: Valores dos ângulos (graus) em função do tempo (cs) - Vista cranial Fonte: Os autores, 2018.

O gráfico 3 apresenta o tempo em que a operadora de checkout permaneceu olhando para o monitor e o gráfico 4 demonstra a frequência de olhares, que atingiu aproximadamente $19,4 \%$ do tempo da atividade de registro de produtos.

Olhares para o monitor $\times$ Tempo (cs)

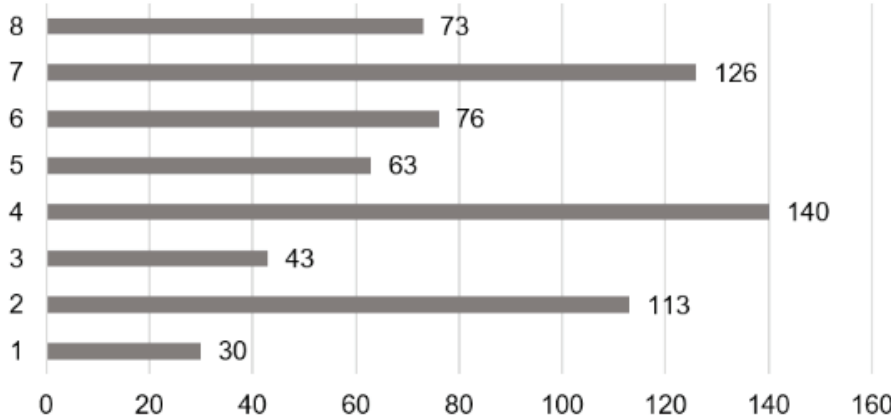

Gráfico 3 e 4: Tempo e frequência de olhares para o monitor Fonte: Os autores, 2018.
Percentual olhares para o monitor (\%)

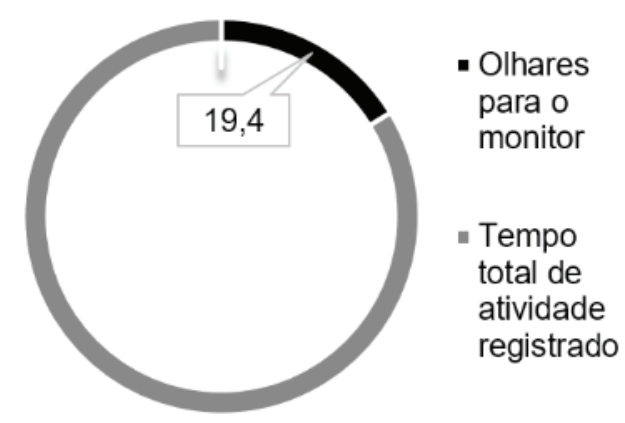

De acordo com dados fornecidos pelo supermercado analisado, uma operadora de checkout registra aproximadamente 3027 produtos por dia de trabalho, correspondendo a cerca de 115 minutos de exercício da atividade (24\% da carga horária diária). O restante do tempo é dedicado as demais atividades atribuídas a sua função (representadas na figura 4). Considerando que a atividade da operadora se apresenta de forma constante, a mesma realiza rotação cervical para a direita por aproximadamente 20,2 minutos por jornada de trabalho.

\subsection{Concepção de um novo posto de trabalho (checkout)}

A partir da AET e do levantamento bibliográfico realizado, foi possível a identificação de problemas relacionados ao ambiente, posto de trabalho e às posturas assumidas durante as atividades. Dessa forma, foi proposto um projeto de um posto de trabalho ergonômico, apresentado nas figuras 7, 8, 9 e 10. O checkout proposto 
possui estrutura linear e dispõe de uma área específica para o posicionamento da cadeira (figura 7).

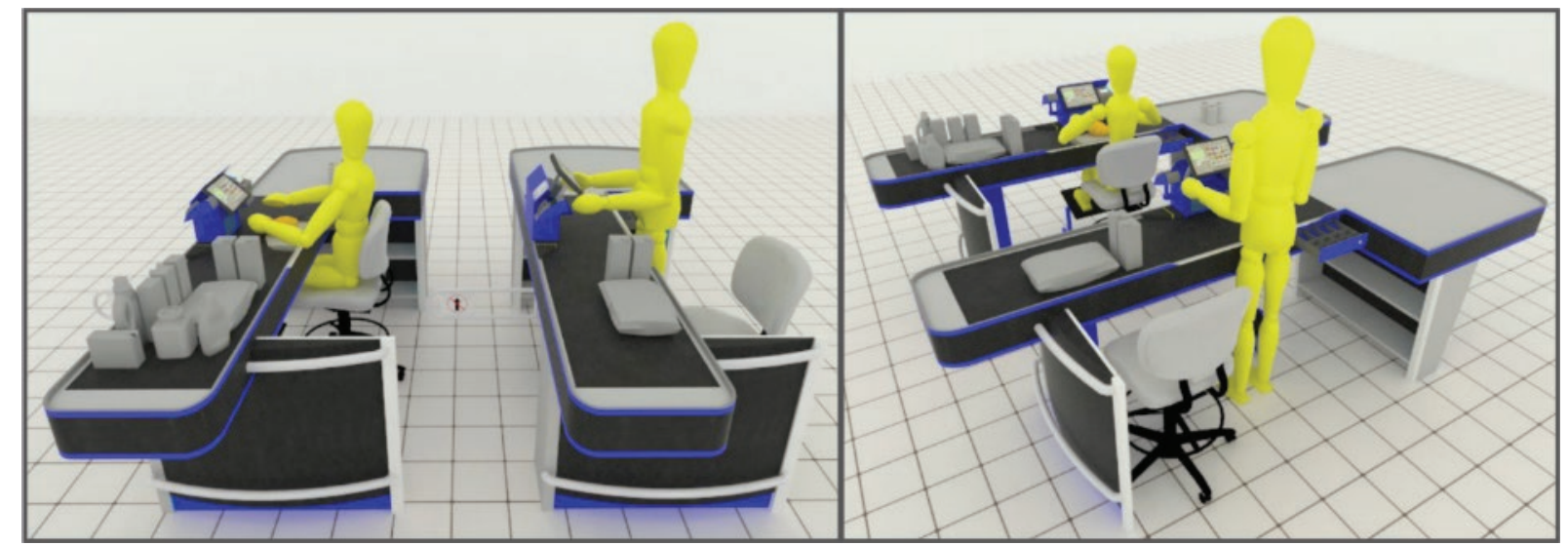

Figura 7: Projeto conceitual de checkout - posicionamento em pé e sentado Fonte: os autores, 2018.

No posto de trabalho, os equipamentos (monitor, impressora, máquina de cartão) e a gaveta para dinheiro foram posicionados frontalmente ao operador (figura 8). Além disso, também foi inserido um apoio para pés (figura 8).

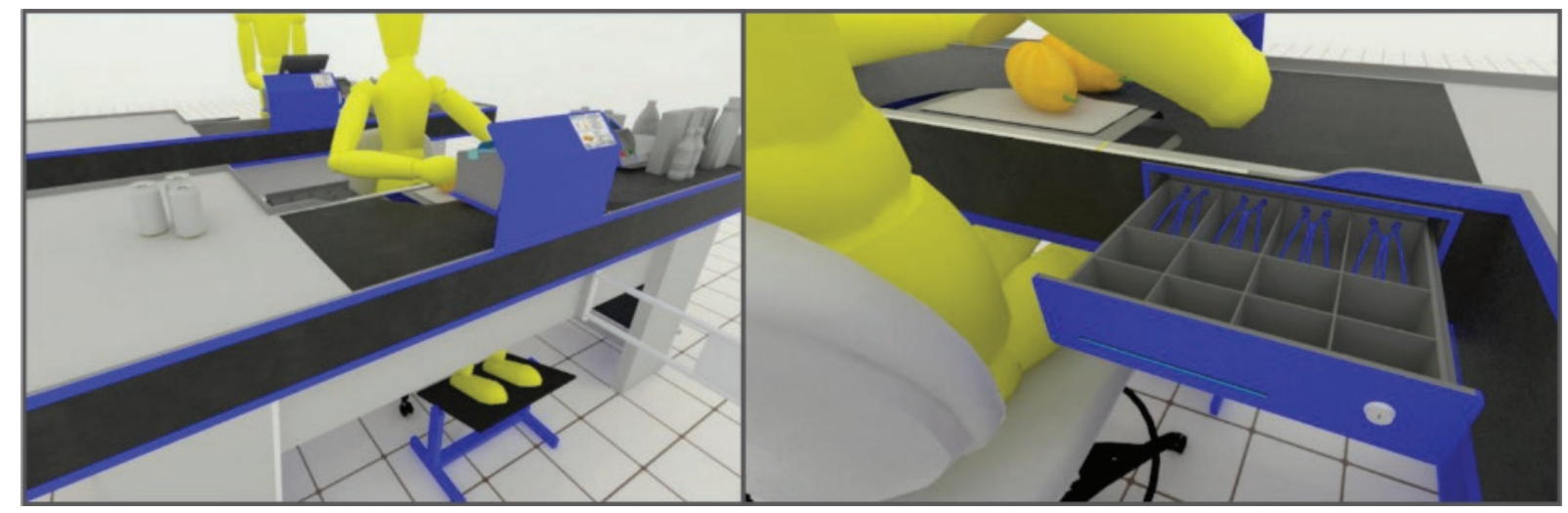

Figura 8: Projeto conceitual de checkout - apoio para pés e gaveta caixa Fonte: os autores, 2018.

O projeto também apresenta dois visores com interfaces amigáveis, sendo um para o operador do checkout e um para o cliente (figura 9).

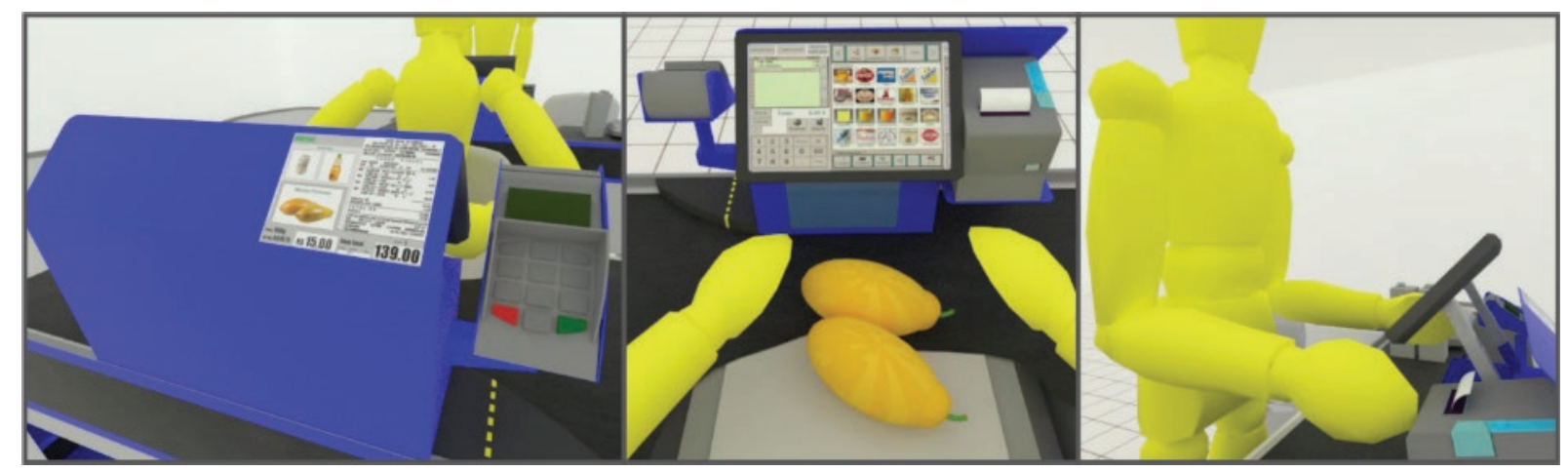

Figura 9: Projeto conceitual de checkout - visor cliente, visor operador e tela articulável. Fonte: os autores, 2018. 
Por fim, o posto apresenta uma esteira eletromecânica com controle manual e por pedal e, sob está, uma balança nivelada à sua superfície, localizada frontalmente ao operador (figura 10).

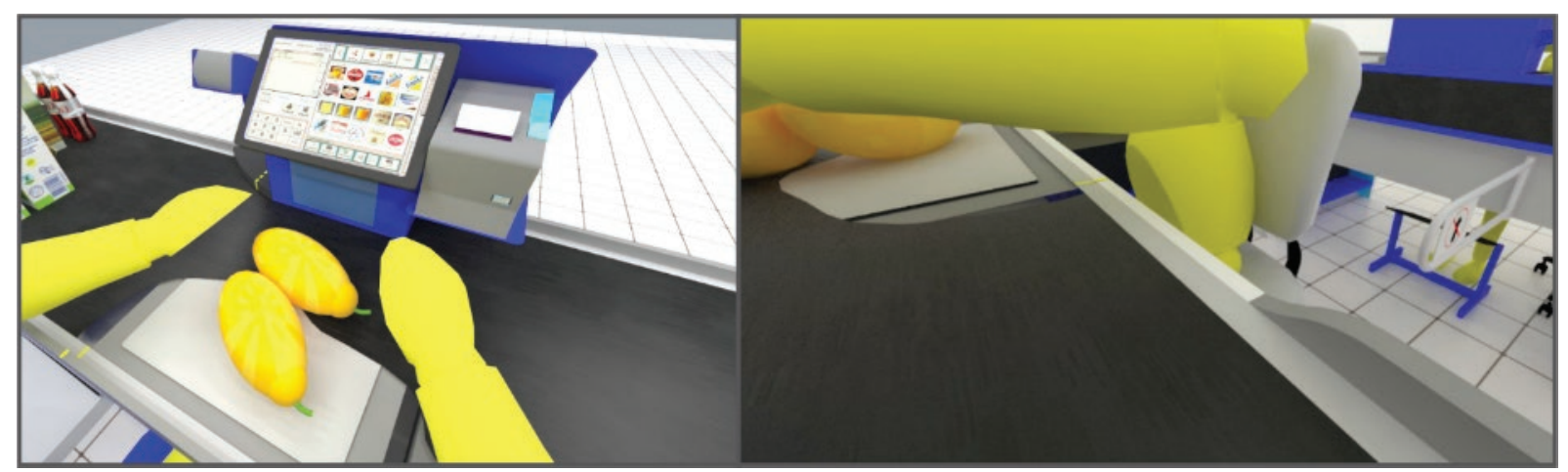

Figura 10: Projeto conceitual de checkout - balança e borda. Fonte: Os autores, 2018.

\section{DISCUSSÃO DOS RESULTADOS}

Mediante os resultados da AET, a seguir serão discutidos os principais fatores de risco identificados e a proposta do novo checkout.

\subsection{Fatores de risco}

No que tange às variáveis ambientais, a temperatura mensurada $\left(24,5^{\circ} \mathrm{C}\right)$ encontra-se $1,5^{\circ} \mathrm{C}$ acima da zona de conforto térmico (20 e 23으) prevista pela NR-17 (BRASIL, 2007). A umidade relativa do ar (65\%) dentro dos parâmetros determinados (não inferior a 40\%), bem como a velocidade do ar (nula), que deve ser inferior a 0,75 m/s. Quanto ao nível de ruído registrado (94.2 dB), considera-se acima do nível aceitável (65 dB) pela NR 17 (BRASIL, 2007).

Quanto a iluminação, as medições nos campos de tarefas visuais apontaram 305 luxes na região do teclado e 225 luxes na superfície do balcão. Considerando os níveis de iluminamento propostos na NBR 5413 (ABNT, 1992) no segmento interior de loja de artigos diversos (mais próximo ao contexto), a iluminação se mostra insuficiente, visto que deveria atingir 500 luxes.

Em relação às atividades associadas aos desconfortos musculoesqueléticos identificados são as de registro de produtos (2) e o ensacamento de produtos (4). Portanto, a análise cinemática realizada focou-se nas situações de risco destas atividades.

Com base na análise cinemática realizada no momento do registro e ensacamento dos produtos, observa-se que a operadora de checkout realiza muitas rotações cervicais para a direita com o intuito de enxergar o monitor, podendo gerar sobrecarga cervical provocada por movimentos repetitivos. Segundo Batiz, Santos e Licea (2009), a multiplicidade de funções dos operadores de caixa, somada à complexidade e à repetição das tarefas repercutem no aumento da carga física e mental dos operadores. De acordo com Moreira, Bastos e Nepomuceno (2011), as lesões musculoesqueléticas relacionadas ao trabalho podem ser resultado do excesso de estresse em função da repetitividade, reclamação dos clientes e da qualidade dos 
postos de trabalho.

Percebeu-se ainda que, devido a área limitada de ensacamento do posto, à medida que as compras são registradas, a operadora de checkout obriga-se a procurar espaços para depositá-las, aumentando as angulações de abdução dos ombros e rotação do tronco. As medidas de abdução dos ombros encontradas neste estudo variaram de 29 a 42 graus no lado direito e de 41 a 99 graus no lado esquerdo. Segundo Tilley e Dreyfuss (2005), a zona de conforto para a abdução dos ombros compreende a angulação de 0 a 40 graus. No que se refere a rotação do tronco, os dados obtidos apontam uma variação de 6 a 29 graus, o que se encontra dentro dos valores aceitáveis apresentados por Tilley e Dreyfuss (2005).

Em relação à coluna cervical, as medidas da inclinação anterior da cabeça, em meio à execução do trabalho, variaram entre 21 e 22 graus. Tilley e Dreyfuss (2005) consideram, como uma faixa ótima de inclinação anterior da cabeça, a angulação de 0 a 15 graus. Para lida e Guimarães (2016), essa angulação não deve ultrapassar 20 graus, sendo que acima de 30 começam a aparecer dores nessa região.

Outro movimento desfavorável observado na operadora, por meio da vista sagital, foi a flexão anterior de tronco, que segundo os estudos de Watckins (2001) e Hall e Brody (2007), pode levar à fadiga da musculatura paravertebral por meio da redução do aporte sanguíneo, resultando em dor. Dul e Weerdmeester (2004) afirmam que a protrusão do tronco demanda esforços contínuos dos músculos e estruturas ligamentares vertebrais, o que aumenta a tensão nos discos intervertebrais e pode repercutir em cervicalgias.

No caso analisado, a execução da atividade de ensacamento é realizada pela própria operadora devido a existência de apenas um ensacador para o atendimento de oito postos ativos. Logo, percebe-se que o número de ensacadores se encontra em desconformidade com o anexo I da NR 17, que prevê no mínimo um ensacador a cada três checkouts em funcionamento (BRASIL, 2007). Esta condição também é destacada no estudo de Carlos et al. (2012), que destacam como consequência a sobrecarga de atividades exercidas pelo operador.

\subsection{Novo posto de trabalho (checkout)}

Souza e Mazini Filho (2015), Vinent e Rodrigues (2015), Teixeira et al. (2009), Batiz, Santos e Licea (2009) e Garcia, Parada e Gutiérrez (2003), apontaram a necessidade de alterações nos postos de trabalho para minimizar os riscos musculoesqueléticos. Diante disso, a partir do diagnóstico das condições inadequadas do posto de trabalho em estudo e pesquisas já realizadas, foi elaborado o projeto de um novo checkout, com melhorias baseadas nas necessidades dos operadores e clientes.

O projeto, apresentado na figura 6, propõe uma configuração formal limpa e linear que visa evitar as constantes rotações corporais do operador. Nesse sentido, Batiz, Santos e Licea (2009) destacam que ângulos e áreas de visão não adaptados exigem dos operadores constantes rotações e inclinações do pescoço. Os cantos e bordas arredondadas do projeto, coerentes com o anexo I da NR 17 (BRASIL, 2007), pretendem reduzir o alto índice de acidentes citados por Batiz, Santos e Licea (2009), os quais destacam que as bordas afiadas da bancada, em contato com mãos ou bra- 
ços, podem provocar ferimentos.

A reconfiguração do posto disponibilizou uma área específica para posicionamento da cadeira quando não está sendo utilizada, durante o trabalho em pé. Quando nesta posição, a operadora analisada permanecia atrás da cadeira, em condições desconfortáveis que limitavam a sua movimentação e aumentavam as forças de cisalhamento sobre a coluna lombar devido a flexão anterior de tronco (IIDA; GUIMARÃES, 2016). Logo, o projeto atende ao anexo I da NR 17, que exige um espaço adequado para livre movimentação do operador e colocação da cadeira, permitindo a alternância da posição em pé e sentada e assegurando posições confortáveis dos membros superiores e inferiores.

Segundo Semensato (2011), o trabalho contínuo, sem alternância com outras tarefas, impede o alívio da fadiga física e mental dos operadores. A mudança de posturas, em tarefas de longa duração, caracteriza-se como pré-requisito de um projeto de posto de trabalho (IIDA; GUIMARÃES, 2016). O apoio para pés independente, também proposto, possibilita maior conforto na posição sentada, conforme figura 7 (BRASIL, 2007).

Os equipamentos (monitor operador/cliente, impressora, máquina de cartão) posicionados frontalmente ao operador, conforme figura 8, evitariam movimentos desnecessários e prejudiciais. Vinent e Rodrigues (2015) corrobora que o posicionamento dos acessórios à frente do colaborador, o alcance fácil à impressora e monitores com ajustes permitem maior conforto e posturas adequadas dos operadores, contribuindo para a realização das atividades. Logo, o teclado digital proposto encontra-se localizado a uma distância máxima de 45 centímetros da borda interna do checkout, atendendo ao anexo I da NR 17 (BRASIL, 2007). Pelo mesmo motivo, a gaveta para dinheiro também foi posicionada frontalmente (figura 7).

Considerando a variação postural, sentada e em pé, sugere-se um monitor touch screen articulável (figura 8). Este permitiria ajustes conforme a posição adotada e atenderia a diferentes perfis de operadores. Neste sentido, Orgel, Milliron e Frederick (1992) ressaltam que a colocação de um teclado ajustável reduz o desconforto no pescoço, nas costas e nos ombros. O projeto também propõe dois visores com interface amigável (operador/cliente) que apresentariam informações como descrição, quantidade, valores e imagens dos produtos.

Diferentemente do posto de trabalho estudado e devido ao seu comprimento maior que 2,70 metros, o projeto dispõe de um sistema com esteira eletromecânica para facilitar a movimentação de mercadorias nos checkouts, conforme orientação do anexo I da NR 17 (BRASIL, 2007). Segundo Batista et al. (2015), o sistema com esteira eletromecânica deve ser adotado para auxiliar no manuseio das mercadorias e não sobrecarregar os operadores em suas atividades com posturas corporais inadequadas. Quanto ao acionamento das esteiras rolantes, Semensato (2011) destaca o controle manual e por pedal, colocado na área de alcance do operador, mantendo seu tronco ereto. A balança atende ao anexo I da NR 17, estando localizada frontalmente, próxima ao operador e nivelada com a superfície do checkout (BRASIL, 2007).

Uma inovação é proposta a partir da instalação da balança sob a esteira, conforme figura 9, criando uma superfície contínua que facilita a funcionalidade e a higienização do posto. Para que o operador saiba quando o produto está sobre a balança, foram aplicadas marcações delimitando o posicionamento do equipamento. Ainda, 
propõe-se uma borda interna rebaixada, a fim de evitar desconforto nos braços.

\section{CONCLUSÃO}

Diante dos resultados obtidos foi possível compreender a complexidade da atividade da operação de checkout devido ao exercício de múltiplas funções que, em condições inadequadas, podem acarretar desconfortos e riscos de lesões musculoesqueléticas. Por meio da realização da AET e pesquisa bibliográfica foi possível identificar os riscos físicos da operação de checkout de supermercado, que determinou requisitos para o desenvolvimento de um projeto conceitual de um posto de trabalho. Neste contexto, os procedimentos adotados se mostraram satisfatórios para a obtenção dos resultados.

Assim, foi possível estabelecer um diagnóstico dos principais fatores de risco (posturais, antropométricos e relacionados aos movimentos repetitivos). Os resultados demonstram, por meio da análise cinemática desenvolvida, que os posicionamentos estáticos com protrusão da cabeça encontram-se acima do intervalo de ângulos recomendados. Da mesma forma, notou-se o aumento progressivo da abdução dos ombros em função da passagem das compras, principalmente no lado esquerdo. Ainda, foram observados movimentos de rotação cervical para a direita, correspondendo a 19,4\% do tempo total da atividade, devido ao registro e verificação dos produtos no monitor, posicionado lateralmente ao operador, o que comprova a realização de movimentos repetitivos. Ainda, destaca-se a flexão anterior do tronco, a qual pode levar à fadiga da musculatura paravertebral por meio da redução do aporte sanguíneo, resultando em dor.

Desta forma, foi possível estabelecer requisitos para o desenvolvimento do projeto do checkout, atendendo às necessidades dos operadores e clientes. Dentre os atributos deste projeto, destacam-se o posicionamento do monitor à frente do operador de checkout, com intuito de reduzir as rotações cervicais, a balança posicionada sob a esteira, para diminuir o levantamento de cargas e esforços repetitivos, bem como o aumento da área de trabalho do operador, possibilitando uma maior variação das posturas na jornada de trabalho. Ainda, sugere-se o aumento da área de ensacamento e o cumprimento da norma NR17 no que se refere ao número de ensacadores, evitando assim, movimentos prejudiciais ao operador de checkout.

Sendo assim, além das contribuições científicas, este estudo pode trazer benefícios no âmbito social, com a implementação dos requisitos no projeto proposto, melhorando o bem-estar do trabalhador no desempenho das suas atividades no checkout. Neste sentido, os resultados da AET foram apresentados para a empresa em estudo por meio de um relatório, a fim de oferecer um feedback sobre o diagnóstico realizado.

Este estudo limitou-se a análise dos aspectos físicos da operação de checkout e, portanto, sugere-se para estudos futuros, abordagem dos aspectos cognitivos e organizacionais. Ainda, salienta-se a possibilidade de investigações a respeito da interface dos monitores propostos no projeto conceitual apresentado. 


\section{AGRADECIMENTOS}

Agradecemos ao Programa de Pós-graduação em Design da UFSC (PPGD/ UFSC), ao Núcleo de Gestão de Design e Laboratório de Design e Usabilidade (NGD -LDU/UFSC), à Coordenação de Aperfeiçoamento de Pessoal de Nível Superior- Brasil (CAPES)- Código de Financiamento 001, ao Conselho Nacional de Desenvolvimento Científico e Tecnológico (CNPq), ao Gean Lima, pela elaboração das imagens conceituais do checkout, ao Supermercado analisado nesse estudo e demais envolvidos.

\section{REFERÊNCIAS}

ABRAHÃO, J. et. al. Introdução à ergonomia: da prática à teoria. São Paulo: Editora Blucher, 2009.

ABRAS (Brasil). Os números do setor. 2017. Disponível em: <http://www.abrasnet. com.br/economia-e-pesquisa/ranking-abras/os-numeros-do-setor/>. Acesso em: 24 jun. 2018.

ASSOCIAÇÃO BRASILEIRA DE NORMAS TÉCNICAS. NBR 5413: iluminância de interiores. ABNT, 1992.

BARROS E. N. C.; ALEXANDRE, N. M. C. Cross-cultural adaptation of the Nordic musculoskeletal questionnaire. International Nursing Review, v. 50, n. 2, p. 101-108, 2003.

BATISTA, D. S. et. al. Análise ergonômica de um supermercado varejista de Campo Grande - MS. In: ENCONTRO NACIONAL DE ENGENHARIA DE PRODUÇÃO. 35., Anais... Fortaleza, Ceará, Brasil, 2015.

BATIZ, E. C.; SANTOS, A. F. dos.; LICEA, O. E. A. A postura no trabalho dos operadores de checkout de supermercados: uma necessidade constante de análises. Production, v. 19, n.1, p. 190-201, 2009.

BRASIL. Portaria no 8, de 30 de março de 2007. Trabalho dos operadores de checkout. Brasília, DF: Diário Oficial da União. 2007. Disponível em: http://www.trt02. gov.br/geral/tribunal2/ legis/CLT/NRs/NR_17.html. Acesso em: 30 jul. 2018.

BRASIL. Ministério da Saúde. Resolução CNS no 466, de 12 de dezembro de 2012. Brasília, DF: Diário Oficial da União. 2013. Disponível em: http://bvsms.saude.gov. br/bvs/saudelegis/cns/2013/res0466_12_12_2012.html. Acesso em: 30 jul. 2018.

CARLOS, A. G.; MEDEIROS, M. F.; NUNES, A. M. A. Avaliação de um operador de caixa baseada na AET. In: SIMPÓSIO DE EXCELÊNCIA EM GESTÃO E TECNOLOGIA. 9., Anais... Natal, Rio Grande do Norte, 2012. 
CORRÊA, V. M.; BOLETTI, R. R. Ergonomia: fundamentos e aplicações. Porto Alegre: Bookman, 2015.

DUL, J.; WEERDMEESTER, B. Ergonomia prática. São Paulo: Edgard Blücher, 2004.

GARCÍA, J.; PARADA, R.; GUTIERREZ, R. Lesiones músculo-esqueléticas de espalda, columna vertebral y extremidades y su incidencia en la mujer trabajadora. Cajeros/as de supermercado. Guía Informativa para el uso de trabajadores/as y delegados/as de prevención, Instituto Canario de Seguridad Laboral, 2003.

GUÉRIN, F et al. Compreender o trabalho para transformá-lo: a prática da ergonomia. São Paulo: Blucher: Fundação Vanzolini, 2001.

HALL, C. M.; BRODY, L. T. Exercício Terapêutico na busca da função. Rio de Janeiro: Editora Guanabara Koogan, 2001.

IIDA, I.; GUIMARÃES, L. B. M. Ergonomia: projeto e produção. 3.ed. São Paulo: Blucher, 2016.

KINOVEA. A microscope for your vídeos. 2018. Disponível em: <https://www.kinovea.org/> Acesso em: 10 jul. 2018.

MARCONI, M. de A.; LAKATOS, E. M. Fundamentos de metodologia científica. 6.ed. São Paulo, Atlas, 2011.

MONTMOLLIN, M. de. A ergonomia. Lisboa: Instituto Piaget, 1990.

MORAES A. de; MONT'ALVÃO, C. Ergonomia: conceitos e aplicações. 2ab, 2000.

MOREIRA, E. J. T.; BASTOS, T. S.; NEPOMUCENO, V. Análise exploratória sobre o posto de trabalho de operadoras de checkout de supermercados de Nova Iguaçu e Rio de Janeiro. In: ENCONTRO NACIONAL DE ENGENHARIA DE PRODUÇÃO, INOVAÇÃO TECNOLÓGICA E PROPRIEDADE INTELECTUAL: DESAFIOS DA ENGENHARIA DE PRODUÇÃO NA CONSOLIDAÇÃO DO BRASIL NO CENÁRIO ECONÔMICO MUNDIAL, 31., 2011, Belo Horizonte. Anais.... Belo Horizonte: 2011.

MTE/SPPE. Classificação Brasileira de Ocupações: CBO 2017. Brasília: MTE, 2017. Disponível em: <http://www.mtecbo.gov.br/cbosite/pages/pesquisas/BuscaPorCodigo.jsf>. Acesso em: 10 jul. 2018.

ORGEL, D. L; MILLIRON, M. J.; FREDERICK, L. J. Musculoskeletal discomfort in grocery express checkstand workers: An ergonomic intervention study. Journal of occupational medicine: official publication of the Industrial Medical Association, v. 34, n. 8, p. 815-818, 1992. 
SANTOS, N. D.; FIALHO, F. (1997). Manual de análise ergonômica do trabalho. 2d. Curitiba: Gênesis, 1997.

SEMENSATO, C. B. Análise ergonômica e intervenções nos postos de trabalho de operadores de caixa de supermercado (checkout). 2011. 74 f. Dissertação (mestrado) - Universidade Estadual Paulista, Faculdade de Arquitetura, Artes e Comunicação, 2011. Disponível em: <http://hdl.handle.net/11449/96262>. Acesso em: 15 jul. 2018.

SOUZA, J. A. C.; MANZINI FILHO, M. L. Análise ergonômica dos movimentos e posturas dos operadores de checkout em um supermercado localizado na cidade de Cataguases, Minas Gerais. Gestão \& Produção, v. 24, n.1, p. 123-135, 2017.

TEIXEIRA, C. S. et al. Fatores associados ao trabalho de operadores de checkout: investigação das queixas musculoesqueléticas. Production, v. 19, n. 3, p. 558-568, 2009.

TILLEY, A. R.; HENRY DREYFUSS ASSOCIATES. As medidas do homem e da mulher: fatores humanos em design. Porto Alegre: Bookman, 2005.

WATKINS, J. Estrutura e função do sistema musculoesquelético. Tradução: Jacques Vissoky. Porto Alegre: ARTMED Editora, 2001.

WISNER, A. Descrição da atividade. In Por dentro do trabalho: ergonomia, método e técnica. São Paulo, FTD/Oboré, 1987.

YIN, Robert. K. Estudo de caso: planejamento e métodos. 4.ed. Porto Alegre: Bookman, 2010. 